\title{
Global and Diffuse Solar Radiation in the United Arab Emirates
}

\author{
Hassan A. N. Hejase and Ali H. Assi
}

\begin{abstract}
This paper presents empirical regression models for predicting the daily and monthly average global solar radiation in the United Arab Emirates (UAE) based on 9-year measured data. It also computes the diffuse solar radiation based on well- established models. The UAE enjoys plenty of sunny days with an annual average of 9.6 daily sunshine hours. This attests to the abundance of solar and its potential to produce clean energy sources.
\end{abstract}

Index Terms-Empirical regression, clearness index, diffuse solar radiation, global solar radiation, prediction models.

\section{INTRODUCTION}

The United Arab Emirates (UAE) experienced a rapid increase in the electricity consumption between 1980 and 2000 according to a World Bank report, published in 2010 [1]; this consumption continues today. Electricity consumption increased from 5.87 billion $\mathrm{kWh}$ in 1980 to about 79.54 billion $\mathrm{kWh}$ in $2009(11,463.63 \mathrm{kWh}$ per capita in 2009) with an annual growth rate of nearly $10 \%$ compared to a world average of $3 \%$ [1]. Large investments in alternate energy sources are expected to change the UAE's energy landscape in the coming years. Abu Dhabi's Economic Vision - 2030 aims at generating 7 per cent of its energy requirements from the renewable resources [2]. In Dubai, UAE, the Mohammed bin Rashid Al Maktoum Solar Park was established in early 2012 as part of a strategy to diversify Dubai's energy sources so that $1 \%$ of its power will be renewable by 2020 and $5 \%$ by 2030 .

These UAE states' initiatives are still insufficient if compared to Germany and Japan both of whom lack the solar energy abundance that the UAE has with over 330 sunny days a year. The abundance of solar energy in the UAE, in particular, and Arabian Gulf region, in general, has triggered the interest of numerous researchers to build weather models that can help scientists and engineers working on building thermal performance, crop analysis, hydraulics, etc. The weather models are a viable alternative in the absence of the measuring stations in the regions where solar data are required. Solar energy can help meet the region's electricity demand.

The potential of solar energy harvesting in the UAE is significant, with an average annual sunshine hours of $3568 \mathrm{~h}$ (i.e. $9.7 \mathrm{~h} /$ day), which corresponds to an average annual solar

Manuscript received February 20, 2013; revised April 20, 2013.

H. A. N. Hejase is with the United Arab Emirates University, Department of Electrical Engineering, Al-Ain, UAE (e-mail: hhejase@uaeu.ac.ae).

A. H. Assi is with the Department of Electrical and Electronics Engineering, Lebanese International University, Beirut, Lebanon (e-mail: ali.assi@liu.edu.lb). radiation of approximately $2285 \mathrm{kWh} / \mathrm{m}^{2}$, i.e. $6.3 \mathrm{kWh} / \mathrm{m}^{2}$ per day [3]. The main limitation of using many weather parameters is the difficulty of obtaining this data due to the high cost and availability of recording equipment.

\section{Methodology}

\section{A. UAE Data Preparation}

The weather database for the cities of Abu Dhabi, Dubai, and Al-Ain in the UAE is provided by the National Center for Meteorology \& Seismology (NCMS) in Abu Dhabi. The data include maximum air temperature $\left(\mathrm{T}\right.$ in $\left.{ }^{0} \mathrm{C}\right)$, average wind speed (WS in knots), sunshine hours (SSH), percent relative humidity $(\mathrm{RH})$ and daily average global solar radiation over a horizontal surface $\left(\mathrm{GSR}\right.$ in $\mathrm{kWh} / \mathrm{m}^{2}$ ). Available weather data for the three UAE cities of Abu Dhabi, Dubai and Al-Ain span the years 2002-2010. The UAE daily average data is obtained from the 2002-2010 data set by averaging data for the three aforementioned UAE cities. The 7-year data for 2002-2008 are used to construct the prediction models while the remaining 2-year data (2009-2010) are employed for testing the models. Leap year days are removed to ensure uniformity of month comparison over the seven year model period.

\section{B. Extraterrestrial GSR and Sunshine-Hours Data for UAE Cities}

The daily average extraterrestrial data for sunshine-hours $\left(\mathrm{S}_{0}\right)$ and extraterrestrial solar radiation on a horizontal surface in $\mathrm{kWh} / \mathrm{m}^{2}\left(\mathrm{G}_{0}\right)$ are computed using the geographical location of the UAE $\left(24^{\circ} 00^{\prime} \mathrm{N}\right.$ and $\left.54^{\circ} 00^{\prime} \mathrm{E}\right)$. Table I displays the computed monthly average of daily $\mathrm{G}_{0}$ and $\mathrm{S}_{0}$ values [3].

TABLE I: EXTRATERRESTRIAL DATA FOR SUNSHINE HOURS AND GLOBAL SOLAR RADIATION IN THE UAE

\begin{tabular}{ccc}
\hline \hline Month & $\mathrm{G}_{0}$ & $\mathrm{~S}_{0}$ \\
\hline JAN & 6.68 & 10.71 \\
FEB & 7.84 & 11.21 \\
MAR & 9.25 & 11.86 \\
APR & 10.49 & 12.56 \\
MAY & 11.26 & 13.15 \\
JUN & 11.56 & 13.46 \\
JUL & 11.43 & 13.31 \\
AUG & 10.84 & 12.79 \\
SEP & 9.73 & 12.12 \\
OCT & 8.30 & 11.42 \\
NOV & 6.98 & 10.83 \\
DEC & 6.33 & 10.54 \\
Annual & $\mathbf{9 . 2 2}$ & $\mathbf{1 2 . 0 0}$ \\
\hline \hline
\end{tabular}




\section{Diffuse Solar Radiation Models}

The design of solar installations requires the determination of solar radiation incident on the plane of the solar collector. Sloped solar collectors receive direct, diffuse and reflected solar radiation. The relationship between monthly average daily diffuse (DSR) and global solar (GSR) radiation incident on a horizontal surface, i.e. $d g=D S R / G S R$, is the most significant parameter. This relationship can be found from direct meteorological observations or through an empirical relationship as studied by various researchers. Most of the meteorological stations in many countries record the global and diffuse radiation amounts. In the UAE, the diffuse radiation measurement data was unavailable, so we will use the appropriate empirical formulas for the estimation of the monthly average of daily diffuse solar radiation.

The diffuse radiation is computed for the UAE using (1) from Page [4], (2) from Klein [5] and Lui \& Jordan [6], (3) from Modi \& Sukhatme for $0.34<\mathrm{k}_{\mathrm{T}}<0.73$ [7], (4) from Kenisarin \& Tkachenkova for $0.15<\mathrm{k}_{\mathrm{T}}<0.8$ [8], and (5) from Alnaser [9]:

$$
\begin{gathered}
d g=1-1.13 k_{T} \\
d g=1.390-4.027 k_{T}+5.531 k_{T}^{2}-3.108 k_{T}^{3} \\
d g=1.4112-1.6956 k_{T} \\
d g=1.191-1.783 k_{T}+0.862 k_{T}^{2}-0.324 k_{T}^{3} \\
d g=-1.897+14.536 k_{T}-26.828 k_{T}^{2}+14.976 k_{T}^{3}
\end{gathered}
$$

Fig. 1 shows the plots of the diffuse to global radiation ratio $(\mathrm{dg}=\mathrm{DSR} / \mathrm{GSR})$ versus the clearness index $\left(\mathrm{k}_{\mathrm{T}}=\right.$ $\mathrm{GSR} / \mathrm{G}_{0}$ ) for the aforementioned models. All considered models for diffuse radiation have nearly linear trends with coefficients of determination greater than $99.3 \%$.

The measured clearness index data for the UAE lie in the range $0.521<\mathrm{k}_{\mathrm{T}}<0.742$. The average daily diffuse solar radiation (DSR) is computed for the UAE models in (1)-(5) using the measured clearness index for the years 2002-2008. The resulting monthly average of daily DSR is shown in Fig. 2. Note the high DSR during the high temperature season with maximum in July of $2.5 \mathrm{kWh} / \mathrm{m} 2$ and a small dip in May. The lowest values are obtained during the low temperature season from October to March.

Fig. 3 shows the ratio of diffuse to extraterrestrial solar radiation (DSR/G0) for the UAE from the years 2002-2008. Note that the contribution of the diffuse solar radiation does not exceed $25 \%$. The highest being in December $(24.4 \%$ for Alnaser model) and the lowest in May (19\% for Alnaser's model). The Page and Klein/Lui \& Jordan models underestimate the diffuse radiation. However, we cannot tell which prediction model is the best (Alnaser's or Page's) due to the absence of measured data.

Fig. 4 shows the monthly average ratio of daily diffuse to global solar radiation for the UAE from 2002-2008 data. Note that the diffuse radiation does not exceed $41.4 \%$ (during December for Alnaser's model) and with a low of $27.4 \%$ (Alnaser) during May. This implies that the direct solar radiation in the UAE will be between 59\% (Dec) and 73 $\%$ (May). Hence, the UAE enjoys clear sky weather conditions for at least $60 \%$ of the year.

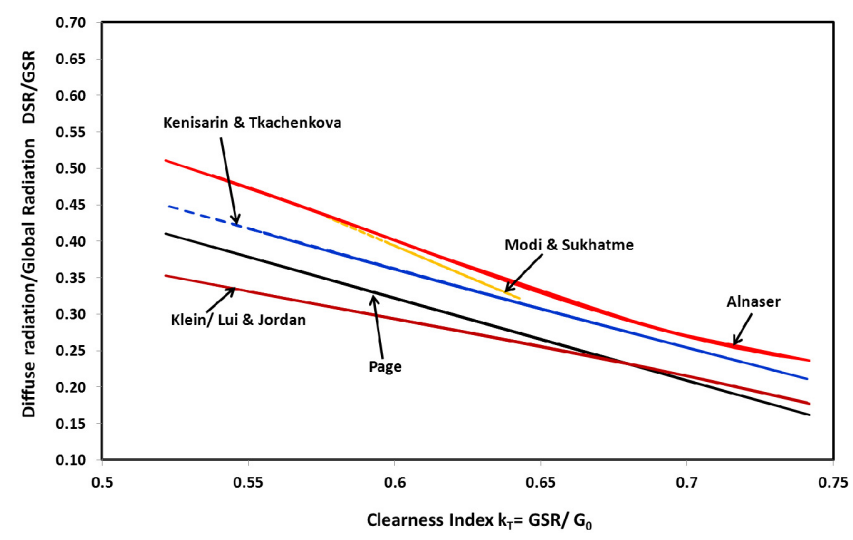

Fig. 1. Ratio of diffuse to global solar radiation as a function of clearness index for the UAE

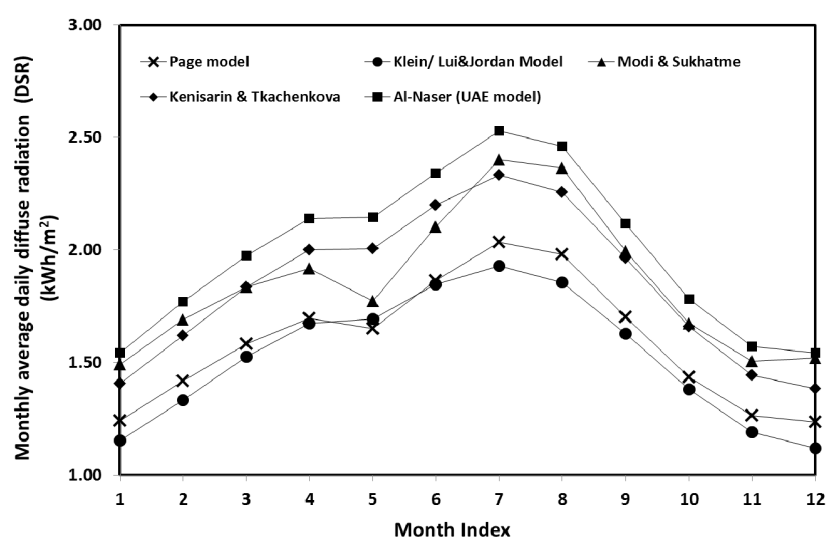

Fig. 2. Predicted monthly average diffuse solar radiation for the UAE

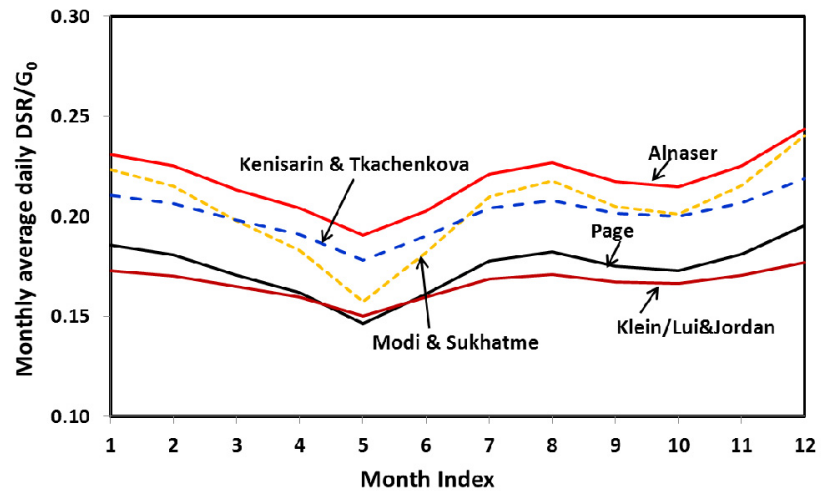

Fig. 3. Predicted monthly average of daily ratio of diffuse to extra-terrestrial solar radiation to for the UAE (years 2002-2008)

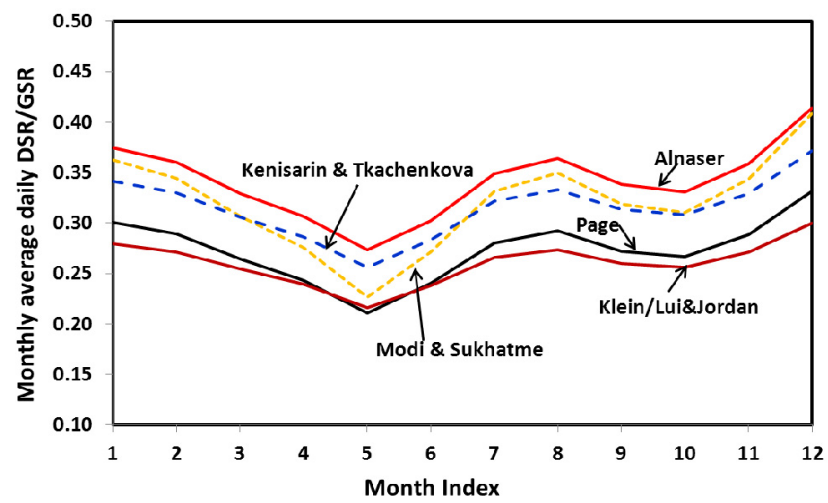

Fig. 4. Predicted monthly average of daily ratio of diffuse to global solar radiation to for the UAE (years 2002-2008) 


\section{Global Solar Radiation Models}

The 7-year average daily GSR and SSH data for the UAE and its three cities are normalized to the extraterrestrial values $G_{0}$ and $S_{0}$ resulting in the normalized data arrays denoted by clearness index $\left(\mathrm{RGSR}=\mathrm{GSR} / \mathrm{G}_{0}\right)$ and Sunshine duration ratio $\left(\mathrm{RSSH}=\mathrm{SSH} / \mathrm{S}_{0}\right)$. The predicted monthly GSR values $\left(\mathrm{G}_{0} * \mathrm{RGSR}\right)$ for each regression model are computed using

$$
G S R=G_{0} f[\mathrm{RSSH}],
$$

where $f[\mathrm{RSSH}]$ represents the various regression models used as displayed in Table II for the UAE and the three cities under study [10]-[15]. The empirical regression models are generated with the help of MATLAB ${ }^{\odot}$ software and verified using IBM-SPSS ${ }^{\odot}$ software.

The measured monthly average daily GSR and sunshine hours for the three UAE cities during the period 2002-2008 are shown in Table III along with values of selected regional gulf cities for comparison [16]. The table also displays the monthly UAE data resulting from averaging data of the three cities. Note that the annual average daily GSR and SSH values for the UAE of $5.96 \mathrm{kWh} / \mathrm{m}^{2}$ and 9.83 hours, respectively, are higher than those reported for other regional gulf cities/countries. A slightly higher GSR is noted in the city of Al-Ain due to higher temperatures (normally $4-5{ }^{0} \mathrm{C}$ higher) and lower humidity as compared to the other UAE cities.

TABLE II: REGRESSION MODELS FOR THE UAE $\left(\mathrm{Y}=\mathrm{GSR} / \mathrm{G}_{0} ; \mathrm{X}=\mathrm{SSH} / \mathrm{S}_{0}\right)$

\begin{tabular}{ll}
\hline \hline Model & Regression equation \\
\hline Linear polynomial [10] & $\mathrm{y}=0.072+0.694 * \mathrm{x}$ \\
Quadratic polynomial [11] & $\mathrm{y}=-0.359+1.763 * \mathrm{x}-0.659 * \mathrm{x}^{2}$ \\
Cubic polynomial [12] & $\mathrm{y}=10.092-38.456 * \mathrm{x}+50.746 * \mathrm{x}^{2}-$ \\
& $21.828 * \mathrm{x}^{3}$ \\
Logarithmic [13] & $\mathrm{y}=0.753+0.561 * \ln (\mathrm{x})$ \\
Log-Linear [14] & $\mathrm{y}=0.880-0.1295 * \mathrm{x}+0.666 * \ln (\mathrm{x})$ \\
Exponential [15] & $\mathrm{y}=0.263 * \exp (1.088 * \mathrm{x})$ \\
\hline \hline
\end{tabular}

TABLE III: ANNUAL AVERAGE DAILy SUNSHINE HOURS AND GLOBAL RADIATION FOR SELECTED GULF CITIES/COUNTRIES

\begin{tabular}{|c|c|c|c|c|}
\hline City & $\mathrm{SSH}$ & $\begin{array}{c}\text { GSR } \\
\left(\mathrm{kWh} / \mathrm{m}^{2}\right)\end{array}$ & $\begin{array}{c}\text { Sunshine } \\
\text { Duration } \\
\text { Ratio }\end{array}$ & $\begin{array}{c}\text { Clearness } \\
\text { Index }\end{array}$ \\
\hline Abu Dhabi (2002-08) & 9.87 & 6.03 & 0.82 & 0.66 \\
\hline Dubai (2002-08) & 9.82 & 5.32 & 0.83 & 0.60 \\
\hline Al-Ain (2002-08) & 9.94 & 6.26 & 0.82 & 0.68 \\
\hline UAE (2002-08) & 9.83 & 5.96 & 0.82 & 0.64 \\
\hline Abu Dhabi [16] & 9.50 & 5.08 & 0.79 & 0.55 \\
\hline Bahrain [16] & 9.20 & 5.42 & 0.77 & 0.60 \\
\hline Doha [16] & 9.59 & 5.25 & 0.80 & 0.58 \\
\hline Kuwait [16] & 8.78 & 5.39 & 0.73 & 0.61 \\
\hline Riyadh [16] & 9.25 & 5.48 & 0.77 & 0.60 \\
\hline
\end{tabular}

Zawilska and Brooks [17] have compared the monthly average daily values of global radiation on a horizontal surface in Durban, South Africa with 25 different worldwide cities in the upper and lower hemispheres. The comparison includes the city of Abu Dhabi, UAE with one-year measured data from Islam et al. [18]. The reported annual average daily GSR of $5.58 \mathrm{kWh} / \mathrm{m}^{2}$ is slightly lower than the computed measured value of $5.96 \mathrm{kWh} / \mathrm{m}^{2}$. Reference [17] shows that Abu Dhabi has the highest GSR among northern hemisphere cities in most months of the year except in June and July where Mosul (Iraq) and Tunis (Tunisia) show higher values. Moreover, our GSR data are more reliable as they are predicted based on 7 years of measured data. The reliability of data for different world cities is highly dependent on the amount of measurement data, and accuracy and type of instrumentation used.

\section{RESULTS AND DISCUSSIONS}

The seven-year (2002-2008) daily mean GSR plots for the regression models of the UAE addressed in Table II show very good correlation between predicted and measured data. Fig. 5 shows the comparisons for the exponential regression model. Note the very good agreement between measured and predicted GSR data for all models. The statistical error parameters resulting from each regression model are computed using MATLAB. A low value of MBE indicates good long term prediction performance. Formulas for computation of the statistical errors are given in [19].

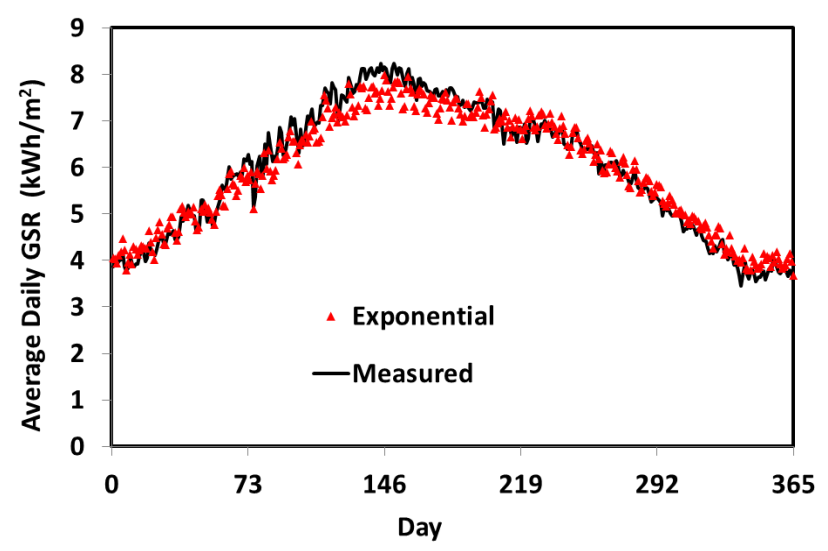

Fig. 5. Comparison of average daily GSR from the exponential regression models for the UAE with measured data for years 2002-2008.

Table IV shows the error statistics resulting from comparison of prediction model data with measured data for the period 2002-2008. Note that all models yield low error statistics with coefficients of determination exceeding $97 \%$.

TABLE IV: ERROR STATISTICS FOR COMPARISON OF AVERAGE DAILY GSR FROM REGRESSION MODELS WITH MEASURED DATA OF UAE FOR 2002-2008

\begin{tabular}{ccccccc}
\hline \hline Error & Linear & Quad & Cubic & Log & $\begin{array}{c}\text { Log- } \\
\text { Linear }\end{array}$ & Expo \\
\hline RMSE & 0.279 & 0.279 & 0.278 & 0.279 & 0.279 & 0.279 \\
MABE & 0.228 & 0.228 & 0.226 & 0.228 & 0.228 & 0.229 \\
MBE & -0.033 & -0.033 & -0.032 & -0.033 & -0.033 & -0.033 \\
MAPE(\%) & 3.902 & 3.898 & 3.866 & 3.899 & 3.899 & 3.905 \\
$\mathrm{R}^{2}(\%)$ & 97.23 & 97.21 & 97.19 & 97.22 & 97.21 & 97.23 \\
\hline \hline
\end{tabular}

The monthly average daily GSR data for all regression models were compared with measured data for the years 2002-2008. Results are shown in Fig. 6. The predictions given by the UAE regression models are in excellent agreement with measured data. The cubic polynomial regression model presents the best prediction and results in error statistics of $\mathrm{RMSE}=0.218 \mathrm{kWh} / \mathrm{m}^{2}, \mathrm{MABE}=0.191$ 
$\mathrm{kWh} / \mathrm{m}^{2} ; \mathrm{MBE}=-0.032 \mathrm{kWh} / \mathrm{m}^{2}, \mathrm{MAPE}=3.27 \%$ and $\mathrm{R}^{2}=$ $98.82 \%$.

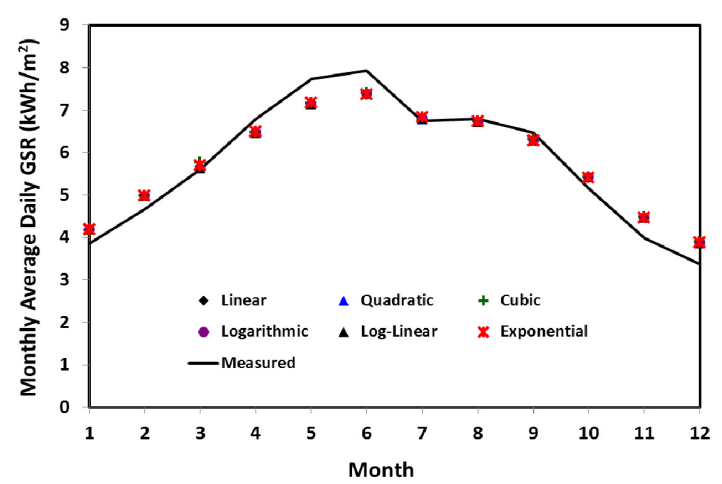

Fig. 6. Comparison of monthly average daily GSR from empirical regression models for the UAE with test data for years 2009-2010.

The six selected empirical regression models (Table II) are validated by computing the predicted daily mean GSR data from these models using the test data set of years 2009-2010. The empirical models compare very well with measured data for the test data period. All models yield coefficients of determination values $\mathrm{R}^{2}$ better than $95 \%$. The cubic polynomial regression model outperforms the other five empirical models yielding $\mathrm{RMSE}=0.456 \mathrm{kWh} / \mathrm{m}^{2}, \mathrm{MABE}=$ $0.376 \mathrm{kWh} / \mathrm{m}^{2}, \mathrm{MBE}=-0.016 \mathrm{kWh} / \mathrm{m}^{2}, \mathrm{MAPE}=6.80 \%$ and $\mathrm{R}^{2}=95.63 \%$. The low values for RMSE, MBE, MABE and MAPE indicate the model's adequacy for UAE weather prediction.

Fig. 7 shows the comparison of monthly mean GSR data between regression models and test data for the years 2009-2010. Note again the very good agreement between predicted and measured data. The statistical error parameters are the lowest for the logarithmic model but all models yield R2 values above $96 \%$ and nearly close RMSE, MBE, MABE and MAPE values. For the logarithmic model we obtained $\mathrm{RMSE}=0.430 \mathrm{kWh} / \mathrm{m} 2, \mathrm{MABE}=0.376 \mathrm{kWh} / \mathrm{m} 2, \mathrm{MBE}=$ $-0.133 \mathrm{kWh} / \mathrm{m} 2, \mathrm{MAPE}=7.42 \%$ and $\mathrm{R} 2=96.44 \%$. Also note that the prediction models underestimate the GSR in the high temperature season (April-September) and overestimate GSR for low temperature season (October-March). The predicted and measured clearness index from 2009-2010 weather data yields are 0.63 and 0.62 , respectively, and with a sunshine duration ratio of 0.80 . These values are close to those obtained from 2002-2008 data (0.64 and 0.82).

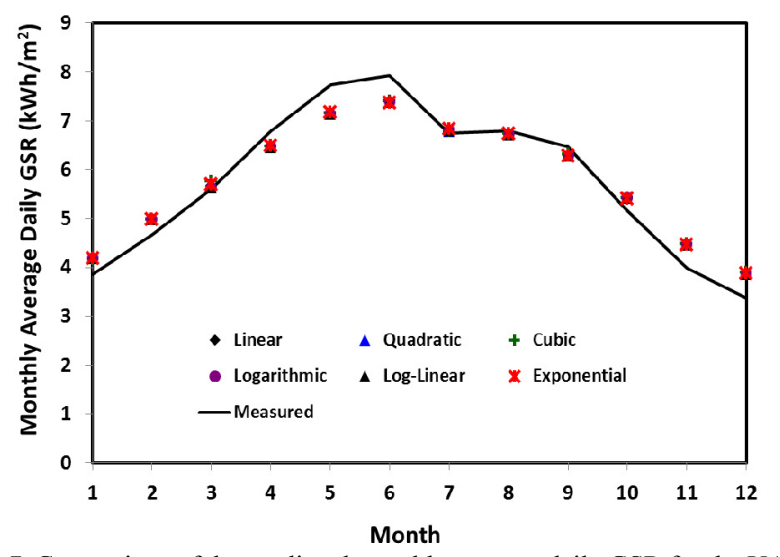

Fig. 7. Comparison of the predicted monthly average daily GSR for the UAE measured test data for the years 2009-2010.
The resulting UAE prediction models were also tested against weather data from the three UAE cities of Abu Dhabi, Dubai, and Al-Ain. Fig. 8 shows the comparison for the exponential models yielding a very good correlation with measured data.

The error statistics shown in Table $\mathrm{V}$ attest to the accuracy of the exponential UAE prediction model for predicting the monthly average daily GSR for the UAE cities.

The measured annual average clearness index and sunshine duration ratio for data for the years 2009-2010 are 0.62 and 0.80 , respectively. These values are also consistent with the values obtained for 2002-2008 data yielding 0.64 and 0.82 , respectively.

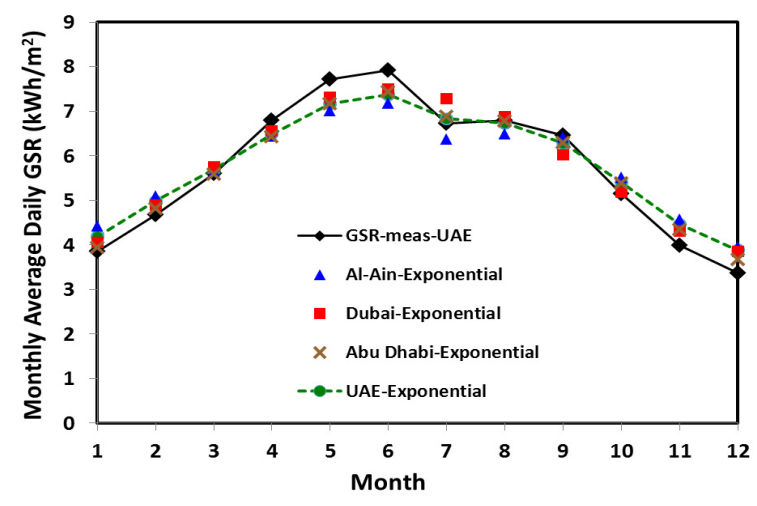

Fig. 8. Comparison of monthly average daily GSR for the UAE and the three cities based on the exponential prediction model for the years 2009-2010.

TABLE V: MONTHLy AVERAGE DAILy GSR ERROR STATISTICS FOR THE EXPONENTIAL REGRESSION MODELS (UAE AND CITIES) FOR 2009-2010

\begin{tabular}{ccccc}
\hline \hline Error & UAE & Al-Ain & Abu Dhabi & Dubai \\
\hline RMSE & 0.357 & 0.479 & 0.293 & 0.336 \\
MABE & 0.311 & 0.4256 & 0.238 & 0.297 \\
MBE & 0.037 & 0.009 & -0.028 & 0.047 \\
MAPE (\%) & 6.08 & 8.21 & 4.28 & 5.52 \\
R $^{2}(\%)$ & 98.87 & 99.04 & 98.35 & 96.41 \\
\hline \hline
\end{tabular}

\section{CONCLUSION}

This work presents classical regression models to predict the global solar radiation (GSR) in the UAE based on available measured data from the cities of Abu Dhabi, Dubai and Al-Ain. The diffuse solar radiation (DSR) was predicted using selected models from the literature due to the absence of measurement data in the UAE. The DSR was correlated with the extraterrestrial solar radiation $\left(\mathrm{G}_{0}\right)$ and GSR. The ratio of DSR to GSR is a minimum of $27 \%$ during May and a maximum of $41 \%$ during December.

The GSR prediction models make use of the measured sunshine hour and GSR data in addition to the geographical location of the UAE (latitude and longitude). The measured data for the period 2002-2008 is used to build the models for the daily average GSR while the available data for 2009-2010 is used to test and validate the prediction models. These prediction models were also validated with measured data for the aforementioned UAE cities with excellent agreement. The low statistical errors obtained and specifically, MBE, indicate the good

A comparison of UAE annual average of daily GSR data 
was made with other Arab state capitals and world cities. Results show that the UAE has the highest GSR and possesses a strong potential for utilization of solar energy. The average clearness index throughout the year was 0.62-0.64 and with a sunshine duration ratio of 0.80-0.82. This means that the UAE enjoys clear sky conditions for most of the year.

\section{ACKNOWLEDGMENT}

The authors would like to thank the National Center for Meteorology and Seismology (NCMS), Abu Dhabi, UAE for providing the weather data.

\section{REFERENCES}

[1] International Energy Agency (IEA Statistics (C) OECD/IEA, http://www.iea.org/stats/index.asp ). Energy Statistics and Balances of Non-OECD Countries and Energy Statistics of OECD Countries. [Online]. Available: http://www.indexmundi.com/facts/united-arab -emirates/electric-power-consumption\#EG.USE.ELEC.KH).

[2] Gulf News. UAE power capacity outpaces demand. [Online]. Available: http://gulfnews.com/business/economy/uae-power-capacity-outpacesdemand-1.1068506, August 31, 2012.

[3] A. Assi and M. Jama. (2012). Prediction of Global Solar Radiation in Abu Dhabi. ISRN Renewable Energy [Online]. Article ID 328237, 10 pages.

[4] J. K. Page, “The estimation of monthly mean values of daily total short wave radiation on vertical and inclined surfaces from sunshine records for latitudes $40^{\circ} \mathrm{N}-40^{\circ} \mathrm{S}$," in Proc. UN Conference on New Sources of Energy, vol. 4, no. 598, pp. 378-390, 1961.

[5] S. A. Klein, "Calculation of monthly average insolation on tilted surface," Sol. Energy, vol. 19, pp. 325-329, 1977.

[6] B. Y. H. Lui and R. C. Jordan, "The interrelationship and characteristic distribution of direct, diffuse and total solar radiation," Sol. Energy, vol. 4, pp. 1-19, 1960.

[7] V. Modi and S. P. Sukhatme, "Estimation of daily total and diffuse insolation in India from weather data," Sol. Energy, vol. 22, pp. 407-411, 1979.

[8] M. M. Kenisarian and N. P. Tkachenkova, "Estimation of solar radiation from ambient air temperature," Appl. Sol. Energy, vol. 28, pp. 66-70, 1992.

[9] W. E. Alnaser, "Empirical correlation for total and diffuse radiation in Bahrain," Energy, vol. 14, no. 7, pp. 409-414, 1989.

[10] G. Podestá, L. Núñez, C. Villanueva, and M. Skanski, "Estimating daily solar radiation in the Argentine Pampas," Agricultural and Forest Meteorol, vol. 123, pp. 41-53, 2004.

[11] B. G. Akinoglu and A. Ecevit, "A further comparison and discussion of sunshine based models to estimate global solar radiation," Energy, vol 15, pp. 865-872, 1990.

[12] T. Samuel, "Estimation of solar radiation for Sri Lanka", Sol. Energy, vol. 47, pp. 333-337, 1991.
[13] D. B. Ampratwum and A. S. S. Dorvlo A, "Estimation of solar radiation from the number of sunshine hours," Appl. Energy, vol. 63, pp. 161-167, 1999.

[14] F. J. Newland, "A study of solar radiation models for the coastal region of south China," Sol. Energy, vol. 31, pp. 227-235, 1988.

[15] N. Elagib and M. G. Mansell, "New approaches for estimating global solar radiation across Sudan," Energy Convers. Mgmt.,vol. 41, pp. 419-434, 2000.

[16] N. Al Mahdi, N. S. Al Baharna, and F. F. Zaki, "Assessment of solar radiation models for the Gulf Arabian countries," Renew. Energy, vol. 2, no. 1, pp. 65-71, 1992.

[17] E. Zawilska and M. J. Brooks, "An assessment of the solar resource for Durban, South Africa," Renew. Energy, vol. 36, pp. 3433-3438, 2011.

[18] M. D. Islam, A. A. Alili, I. Kubo, and M. Ohadi, "Measurement of solar-energy (direct beam radiation) in Abu Dhabi, UAE," Renew. Energy, vol. 35, pp. 515-519, 2010.

[19] H. A. N. Hejase and A. H. Assi, "MATLAB-assisted regression Modeling of Mean Daily Global Solar Radiation in Al-Ain, UAE," in Engineering Education and Research using MATLAB, Ali H. Assi, Ed. Intech publisher, Chapter 8, pp. 195-218, 2011.

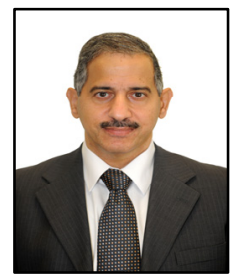

Hassan A. N. Hejase was born in Torreon, Mexico. $\mathrm{He}$ received a $\mathrm{Ph} . \mathrm{D}$ in electrical engineering from Syracuse University, NY, USA in 1987. He served on the faculty of the electrical engineering department a the University of Kentucky, USA (1987-1993), Monterrey Tech (ITESM), Mexico (1993-1995), and American University of Beirut, Lebanon (1995-1996). Since 1996 he has been with the United Arab Emirates University where he is now an associate professor in the department of electrical engineering. He was EE department chairman between 2000-2010 where he led ABET accreditation efforts as well as proposal preparation for establishing the MSc program in addition to proposals for improving current undergraduate programs. His research interests are in the areas of computational electromagnetics, bio-electromagnetic with the use of nanoparticles for hyperthermia applications, and modeling of renewable energy systems. He has over 50 journal and conference publications. Dr. Hejase is a member of IEEE.

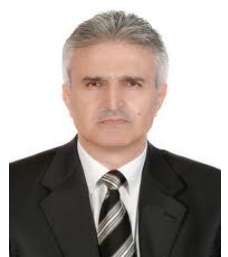

Ali H. Assi received his Ph.D. degree in Electrical Engineering from Ecole Polytechnique De Montreal. In January 1998, he joined Texas Instruments in Ottawa, where he worked as an ASIC Applications support engineer. In June 1999, Dr. Assi moved to Texas Instruments in Dallas as ASIC design engineer. In September 2000, he joined the Department of Electrical Engineering at the American University of Beirut (AUB) as a urer. He served with the faculty of electrical engineering at the United Arab Emirates University (UAEU) between 2001-2012 as assistant and associate professor. Since September 2012, he has been a professor of electrical and electronic engineering at the Lebanese International University, Beirut, Lebanon His research interests include VLSI/CAD and Mixed-Signal Analog/Digital circuits design, and Photovoltaics/Solar cells. He has published more than 85 papers in peer reviewed journals and conference proceedings. Dr. Assi is senior member of the IEEE. 